\title{
Numerical Estimation of Heat Recovery within a Distributed Incinerator Using Water and Hydrocarbons as Working Fluids
}

\author{
Hikaru Yamashiro ${ }^{1,}$, Tomoyasu Yara ${ }^{1}$, Kenji Fukutomi ${ }^{2}$ \\ ${ }^{1}$ National Institute of Technology, OKINAWA College, Nago, Japan \\ ${ }^{2}$ THOMAS Technical Research Company, Uruma, Japan
}

Email address:

hyama@okinawa-ct.ac.jp (H. Yanashiro)

${ }^{*}$ Corresponding author

\section{To cite this article:}

Hikaru Yamashiro, Tomoyasu Yara, Kenji Fukutomi. Numerical Estimation of Heat Recovery Within a Distributed Incinerator Using Water and Hydrocarbons as Working Fluids. International Journal of Mechanical Engineering and Applications. Vol. 7, No. 1, 2019 , pp. 8-16. doi: 10.11648/j.ijmea.20190701.12

Received: January 7, 2019; Accepted: March 13, 2019; Published: April 3, 2019

\begin{abstract}
The potential of a cogeneration system combined with a small combustion furnace was investigated in this study. The heat transfer between the exhaust gas and working fluid flowing in a spiral tube heat exchanger was estimated numerically and the amount of vapor generated was predicted. The combustion chamber had a $0.49 \mathrm{~m}^{3}$ inside volume with a chimney height of $2.5 \mathrm{~m}$ and an inner diameter of $0.28 \mathrm{~m}$. A uniform gas side temperature condition that was referenced from the results of a preliminary experiment and a computational fluid dynamics simulation were adopted to simplify calculations and clarify the effects of working fluids. The amounts of heat recovery when utilizing water and other types of working fluids (Pentane, Butane) were compared. The most effective tube length considering pressure drop and phase change was also predicted. Isentropic theoretical thermal efficiency and T-s diagrams are analyzed to evaluate the vapor-power conversion rate using waste heat. As a result, a potential the heat recovery rate of approximately $100 \mathrm{~kW}$ at a $150 \mathrm{~kg} / \mathrm{h}$ mass flow rate is expected.
\end{abstract}

Keywords: Heat Transfer, Thermal Recycle, Incinerator, Working Fluids, Cogeneration System

\section{Introduction}

The practical use of cogeneration systems supplying both electric power and hot waste have been gradually increasing, especially in large-scale combustion facilities [1]. On the other hand, for relatively small incinerator having furnace volume of $1 \mathrm{~m}^{3}$ or less, it has been considered that there are several obstacles to their practical use as cogeneration system, such as a lack of exhaust heat, instable power generation, and low economic benefit, so on. However, in recent year, the high temperature type incinerator having several forced combustion burners have been developed, and these are expected to be make practical use as a heat recovery system so called "micro-cogeneration". Therefore, the reasonable thermal design with applicable numerical estimations are crucial due to make discussions on the potential of these combustion equipment [2-3].

Previous studies regarding heat recovery can be classified into three major categories: those focused on heat exchangers [4-8], working fluids [9], and system performance [10-11]. The qualitative classification of waste heat is performed based on temperature levels of approximately $373 \mathrm{~K}$ and 523 $\mathrm{K}$ as reference values. On the other hand, regarding the thermal design of heat exchangers, heat transfer with phase change and/or two-phase flow have been attracting in academic field for long time. For recent instance, the studies dealing with two-phase flow model and numerical simulation inside porous media are presented [12-15]. These studies also help to understand heat transfer enhancement process and give the methodology for the development of latent heat recovery system with phase change process.

In industrial fields on the refrigeration and air conditioning systems, methodology of thermal design of equipment such as the evaporators and condensers have already been established [2, 3]. However, when dealing with hightemperature exhaust gas, the heat exchanger for heat 
recovery introduces the problem of decreased performance because of high-temperature corrosion, deposit layers, and so on practical issues. In many cases, the volumetric flowthrough-type heat exchangers have been utilized considering in the effect of radiation heat transfer in large-scale combustion furnaces [4]. In present study, spiral tube-type heat exchanger is focused, since it considered to be applicably installed into the narrow space in the small-type incinerator.

The heat recovery systems are recently investigated with focusing on waste heat below $373 \mathrm{~K}$. For example, evaluation of the heat transfer performance of a spiral capillary tube is performed by Yamashita and Utaka [5], analyzed heat recovery in the heat exchanger of a regenerative steam cycle [6-10]. And the investigation in order to obtain the optimal working fluids are performed by the comparisons of Rankin cycle on the equilibrium-state diagrams [11]. However, there have been few studies focusing on quantitative verification utilizing practical data.

Based on the above research review, the potential of cogeneration system combined with the forced-combustion incinerator (view Figure 1) have been discussing in this study. As a first step, this paper presents the results of numerical estimation on heat transfer between the working fluid flowing inside a spiral tube with a pressure drop and the uniform gas side temperature. Discussion regarding the effects of working fluids for the heat recovery rate and the isentropic theoretical power conversion rate is also included.

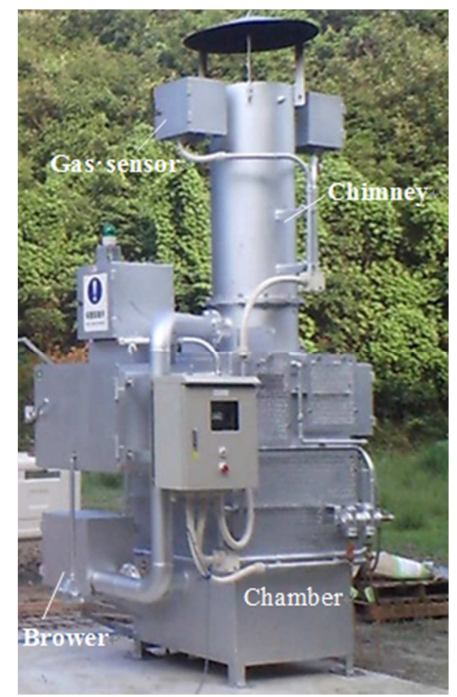

Figure 1. Forced combustion type incinerator.

\section{Outline of Incinerator}

\subsection{Dimensions and Features}

Figure 1 shows a snap shot of the forced combustion incinerator developed by Thomas Co., Ltd. The combustion chamber has a $0.49 \mathrm{~m}^{3}$ inside volume with a chimney height of $2.5 \mathrm{~m}$, and it's inner and outer diameter of 0.28 and $0.3 \mathrm{~m}$ respectively. Waste materials in the chamber are burned by a main burner. The secondary burner is utilized to re-burn the generated gas. Additionally, fresh air is supplied from the duct through nozzles to enhance combustion. These combustion and exhaust processes effectively reduce the amounts of dioxins until less than $2.5 \mathrm{ng} / \mathrm{m}^{3} \mathrm{~N}$ in the exhaust gas. Measurements of temperature and the concentrations of exhaust gases, as well as the efficient control of combustion and gas cooling are performed. Preliminary experiments revealed that the temperature in the furnace reached a quasisteady state after $20 \mathrm{~min}$ with relatively large-scale temperature fluctuations between $200^{\circ} \mathrm{C}$ and $300^{\circ} \mathrm{C}$ near the inside wall of the combustion furnace.

\subsection{Temperature Distribution}

Initially, the temperature distribution in the furnace was investigated by utilizing simulation software (Fluent 6.2). Figure 2 presents the results of temperature distributions at the quasi-steady combustion state. This calculation was performed using finite element method (number of elements and contacts: 94,237 and 61,054), based on the $k$ - $\varepsilon$ turbulence model. A certain volume of heat source as generation terms was placed at the lower left side in the furnace. The temperature of the heat source was given to be around $1100^{\circ} \mathrm{C}$. The generated gas from the heat source was reheated by the secondary burner at the inlet of chimney where modeled as the secondary heat source terms of temperature around $900^{\circ} \mathrm{C}$. The air flow supplied from the nozzles (hole) on the duct surface were given at $20 \mathrm{~m} / \mathrm{s}$. As the boundary condition, the heat transfer between the wall and outside air assumed to be constant at $60 \mathrm{kw} / \mathrm{m}^{2} \mathrm{~K}$, [2]. And these assumed values as the boundary and/or initial conditions were modified to be approximately approach to the gas temperature measured utilizing the thermocouples installed in the vicinity of the inner wall.



Figure 2. Temperature distribution in incinerator.

The temperature profile shows that the waste continued burning at temperatures between $1,100^{\circ} \mathrm{C}$ and $700^{\circ} \mathrm{C}$ without continued operation of the main burner and the exhaust gas was re-burned at approximately $800^{\circ} \mathrm{C}$ by a secondary burner at the exit of the chamber. The generated gas is cooled rapidly by a spray nozzle installed near the entrance of the duct installed in the chimney. Next, the exhaust gas rises in the chimney as the temperature decreases based on air injections from the duct. The exhaust temperature into the 
outside air is approximately $200^{\circ} \mathrm{C}$. The velocity of the exhaust gas in the chimney was estimated to be approximately $2-3 \mathrm{~m} / \mathrm{s}$. The dimensions of the furnace are summarized in Table 1, where the notation corresponds to Figure 3 shown in the next section.

Table 1. Dimensions of incinerator.

\begin{tabular}{lllll}
\hline Chimney $[\mathrm{m}]$ & $\mathrm{H}$ & $D_{i}$ & $D_{o}$ & $y_{0}$ \\
& 2.5 & 0.28 & 0.3 & 0.05 \\
Chamber $[\mathrm{m}]$ & $\mathrm{h}$ & $\mathrm{a}$ & $\mathrm{b}$ & $\mathrm{c}$ \\
& 1.6 & 0.7 & 0.7 & 1.0 \\
\hline
\end{tabular}

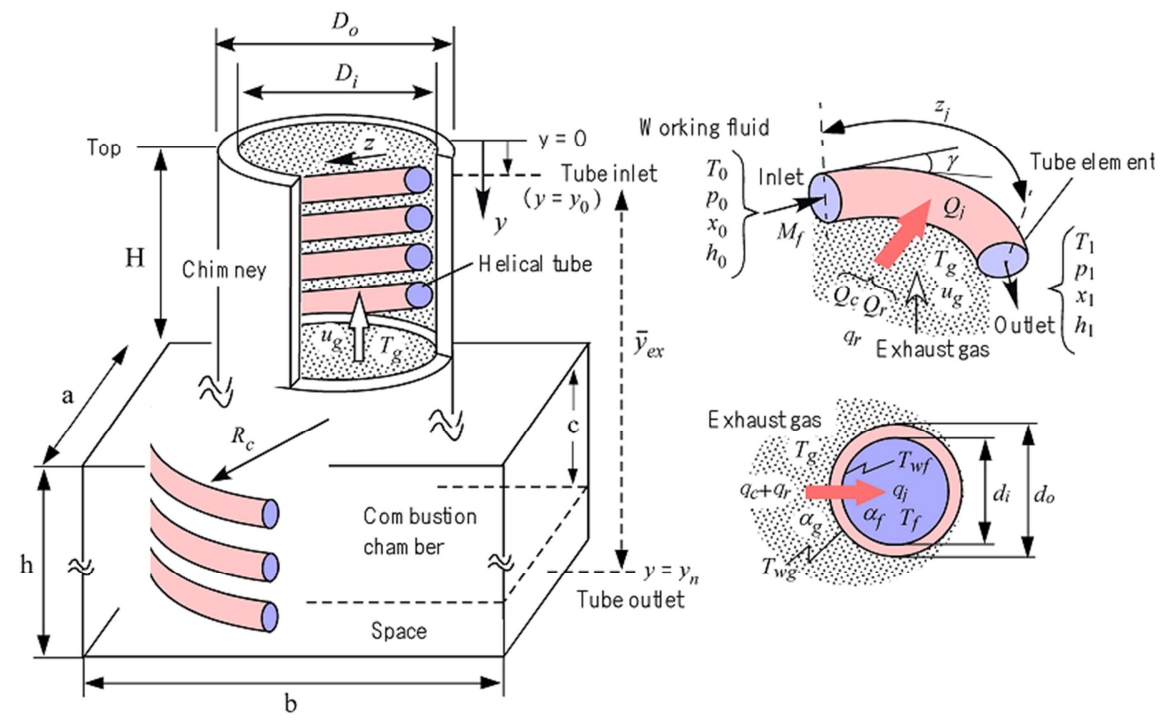

Figure 3. Combustion furnace with spiral tube, and heat transfer model and coordinates.

The heat and mass balance for the element of the spiral tube is expressed as

$$
Q_{j}=M_{f}\left(h_{1}-h_{0}\right)
$$

where $h$ is the specific enthalpy of the working fluid and $Q_{j}$ is the heat transfer rate from the exhaust gas to the working fluid across the tube wall element with the number " $j$ ". The subscripts 0 and 1 represent inlet and outlet of the tube element, respectively. The $Q_{j}$ for the steady state is expressed as

$$
\begin{gathered}
Q_{j}=\alpha_{f}\left(T_{w f}-T_{f}\right) \pi d_{i} z_{j} \\
Q_{j}=2 \pi z_{j} \lambda\left(T_{w g}-T_{w f}\right) / \ln \left(d_{o} / d_{i}\right) \\
Q_{j}=Q_{c}+Q_{r}=\left\{\alpha_{g}\left(T_{g}-T_{w g}\right)+\varepsilon a \sigma\left(T_{g}^{4}-T_{f}^{4}\right)\right\} \pi d_{o} z_{j}
\end{gathered}
$$

where $\alpha$ is the heat transfer coefficient, and $\lambda$ is the thermal conductivity. The subscripts " $w$ ", " $f$ ", " $g$ " and " $i$ " refer to the wall, fluid, gas, and inside respectively. And subscripts " $w f$ " and " $w g$ " refer to the wall at gas side and the wall at working fluid side respectively. The values of $\alpha_{f}$ and $\alpha_{g}$ obtained from the correlation equations proposed by Dittus-Boelter and Chen referred in [2]. The $Q_{j}$ is represented by the sum of the

\section{Numerical Calculation}

\subsection{Heat Transfer Model and Coordinates}

Figure 3 presents the schematics of a combustion furnace with a heat exchanger. On the right side, enlarged view of heat and mass transfer model for an element of a spiral tube represented. A single stain-less steel pipe (SUS430) forms a spiral along the inner wall of the chimney of the combustion chamber. The working fluid supplied through the tube inlet flows at a constant mass flow rate $M_{f}$ according the equation of continuity. The inside $d_{i}$ and outside $d_{o}$ tube diameters are $10 \mathrm{~mm}$ and $12 \mathrm{~mm}$, respectively. convection and radiation terms $Q_{c}$ and $Q_{r}$ respectively in the gas side, as shown Eq. (4). The $\varepsilon$ and $a$ are the emissivity and absorptivity values for the radiation heat transfer on the gas side, respectively, and $\sigma$ is the Boltzmann constant.

Temperature of working fluid $T_{f}$ represents the arithmetic average value evaluated by Eq. (5).

$$
T_{f}=\frac{1}{2}\left(T_{f 0}+T_{f 1}\right)=T_{f 0}+\frac{1}{2} \Delta T_{f}
$$

where the subscripts $f, 0$ and 1 refer to the fluid, inlet and outlet for the tube element, respectively.

The exhaust gas temperature of $T_{g}$ is given by an approximate equation that is evaluated based on the results of computational fluid dynamics simulations (see Figure 2). This equation is defined as

$$
T_{g}(y)=c_{n} y^{n}
$$

where the coefficients $c_{n}(n=0,1,2,3)$ take on different values depending on the combustion state in the chamber. The vertical coordinate $y$ can be transformed into the spiral coordinate $z$ along a tube length with the spiral angle $\gamma$, as the equation $y=y_{j}=z_{j} \sin \gamma$. In this study, to clarify the effects of a several kinds of working fluids on heat transfer characteristics, the temperature distributions on the gas side 
were simplified as eq. (6). The emissivity $\varepsilon$ and absorptivity $a$ of the gas side were set to the maximum values of $\varepsilon=a=1$ Table 1 present the temperature coefficients $c_{n}$ which obtained in the preliminary experiment when the incinerator keeped at the steady state without gas cooling by the air nozzles. In this study, the gas side's temperature was used these values of $\mathrm{cn}$ for the assumption of gas side's temperature as boundary condition.

Table 2. Values of $c_{n}$ at the steady state in combustion.

\begin{tabular}{lllll}
\hline $\mathbf{n}$ & $\mathbf{c}_{\mathbf{0}}$ & $\mathbf{c}_{\mathbf{1}}$ & $\mathbf{c}_{\mathbf{2}}$ & $\mathbf{c}_{\mathbf{3}}$ \\
\hline 3 & 498.5 & 52.72 & 13.03 & 0.086 \\
\hline
\end{tabular}

\subsection{Pressure Drop}

The pressure drop of the working fluid along the tube element's inside wall can be expressed as

$$
\Delta p_{j}=p_{0}-p_{1}=\frac{\rho_{f}}{2}\left\{\left(\frac{\rho_{0}}{\rho_{1}}\right)^{2}-1\right\} u_{0}^{2}+\rho_{f} g\left(y_{0}-y_{1}\right)+\Delta p_{l}
$$

where $\Delta p_{j}$ is the element's total pipe loss sum of friction loss and curved pipe loss. And where $\rho, u$ and $g$ represent density, velocity and gravitational acceleration. And subscript " 0 " and " 1 ", respectively. This value therefore can be expressed as

$$
\Delta p_{l}=\rho_{f} g\left(\Delta z_{b}+\Delta z_{f}\right)=\frac{\rho_{f}}{2}\left(f_{j} \frac{z_{j}}{d_{i}}+\zeta_{j}\right) u_{0}^{2}
$$

where $f_{j}$ is the pipe friction coefficient and $\zeta_{j}$ is the curved pipe loss coefficient for the tube element. These values are given by the correlation equations proposed by Ito et al. [1].

\subsection{Calculation Procedure}

Calculation is performed in series of tube element based on the boundary conditions of B. C. $r=r_{o}: T=T_{g}, z=z_{0}, z_{1}$ : $M_{f 0}=M_{f l}$ (constant mass flowrate).

The values $\left(p_{0}, T_{f 0}, M_{f}\right)$ of working fluid at the entrance to the tube where corresponds to the top of chimney and the temperature difference $\Delta T_{f}(=0.1 \mathrm{~K})$ are given as the initial conditions. The obtained values of $T_{f 1}$ and/or $T_{f}$ (by eq.5) and $p_{I}$ are utilized for the calculation of the thermal properties. The thermal properties are obtained from the subroutine program in the NIST Ref-Prop Ver. 9 [12].

The enthalpy at the inlet $h_{0}\left(p_{0}, T_{f 0}\right)$ and outlet $h_{l}\left(p_{l}, T_{f l}\right)$ are also utilized in these calculations. $Q_{j}$ can be estimated from Eqs. (1) and (5), where the unknown values $T_{w g}, T_{w f}$, and $z_{j}(j=1)$ are given by Eqs. (2) through (6). Based on the calculated values, the thermal properties of working fluid are then the recalculated and all unknown values are calculated to derive a final solution. These calculation procedures perform sequentially from $j=1$ until $n$, where the desired superheated vapor can be obtained. Regarding the transition of the phase change, the temperature difference between the calculated value of $T_{f 1}$ and the saturation temperature of $T_{s l}$ was less than 0.001 (i.e. $T_{s l}-T_{f}< \pm 0.001$ ). These values represent the boiling incipience point and dry out point, respectively. Therefore, the three heat transfer regions can be specified by $T_{f l}<T_{s I}$ for the compressed liquid, $T_{s I}=T_{f I}$ for two-phase transfer, and $T_{s l}<T_{f l}$ for the superheated vapor.

The calculation in the two-phase region $\left(T_{f 0}=T_{f 1}\right)$, the quality at the inlet $x_{0}$, and $\Delta x$ are given as initial conditions. The outlet $x_{l}$ and $Q_{j}$ are calculated sequentially, similar to the above calculations. The enthalpy $h_{l}$ was defined as

$$
h_{1}=\left(1-x_{1}\right) h^{\prime}+x h^{\prime \prime}=h^{\prime}+x_{1} r \text {, where } h^{\prime} \text { and } h^{\prime \prime} \text { refer to }
$$

the saturation liquid and saturation vapor, respectively. Next, the unknown values were calculated utilizing the procedure described above. The calculations proceed from the saturation liquid $\left(x_{0}=0\right)$ to the saturation vapor $\left(x_{1}=1\right)$, which represents the end of the two-phase region. The values of $h^{\prime}$ and $h^{\prime \prime}$ are based on the saturation temperature $T_{s l}$ for the calculated outlet pressure $p_{l}$.

\subsection{Overall Heat Recovery Rate and Tube Length}

The overall tube length of the heat exchange $Z_{e x}$ is defined by Eq. 9 . The overall heat recovery rate $Q_{h}$, and the pressure drop $\Delta p_{e x}$ along $Z_{e x}$ are also defined by Eq. (9).

$$
Z_{e x}=\sum_{j=1}^{n} z_{j}, Q_{h}=\sum_{j=1}^{n} Q_{j}, \Delta p_{e x}=\sum_{j=1}^{n} \Delta p_{j}
$$

$n$ corresponds to the end of tube, where the working fluid has reached the desired temperature or super heat $\Delta T_{\text {sup }}$. The pressure drop per unit length is defined by

$$
\Delta \bar{p}_{e x}=\Delta p_{e x} / Z_{e x}
$$

The vertical coordinate $y_{n}$ of the $n$th tube element of the spiral-wound single tube is expressed in terms of the length $z_{j}$ and spiral angle $\gamma$ as

$$
y_{n}=y_{0}+\sum_{j=1}^{n} z_{j} \sin \gamma
$$

where $y_{0}$ is the vertical distance of the tube's entrance from the top of the chimney as shown Figure 3. Therefor the overall tube length of heat exchanger is expressed as $y_{e x}$,

$$
y_{e x}=\sum_{j=1}^{n} z_{j} \sin \gamma=N \pi\left(D_{i}-d_{o}\right) \tan \gamma
$$

where $D_{i}$ is the inner diameter of the chimney, $d_{o}$ is the outer diameter of the tube, and the $N$ is the number of turns along the total tube length. The spiral tube angle is defined by the following equations.

$$
\begin{gathered}
\gamma=\tan ^{-1}\left(\frac{d_{0} / 2}{2 R_{c}}\right) \text { or } \\
\gamma=\tan ^{-1}\left(\frac{d_{0} / 2}{D_{i}}\right) Z_{e x}=H / \sin \gamma, \\
Z_{e x}=h / \sin \gamma
\end{gathered}
$$


As shown Figure 3, based on the assumption that the spiral tube for the heat exchanger runs from the near top of the chimney to the bottom of the combustion chamber, $Z_{e x}$ is geometrically defined as the maximum tube length $Z_{e x, \max }$ of a perfect circular coil without gaps.

The dimensions of the spiral tube and the initial conditions are summarized in Table 3 and 4.

Table 3. Dimensions of spiral tube.

\begin{tabular}{llll}
\hline Material & $d_{o}[\mathrm{~mm}]$ & $\boldsymbol{d}_{\boldsymbol{i}}[\mathrm{mm}]$ & $\gamma[$ deg. $]$ \\
\hline Sus430 & 12.0 & 10.0 & 1.0 \\
\hline
\end{tabular}

Table 4. Initial conditions of working fluid.

\begin{tabular}{llll}
\hline Kinds & $\boldsymbol{T}_{\boldsymbol{f} 0}[\mathbf{K}]$ & $\boldsymbol{M}_{\boldsymbol{f}}[\mathbf{k g} / \mathbf{h}]$ & $\boldsymbol{p}_{\boldsymbol{0}}[\mathbf{M P a}]$ \\
\hline Water Butane Pentane & 300 & $10-150$ & 2.0 \\
\hline
\end{tabular}

\section{Numerical Results}

\subsection{Tube Length and Amount of Heat Recovery}
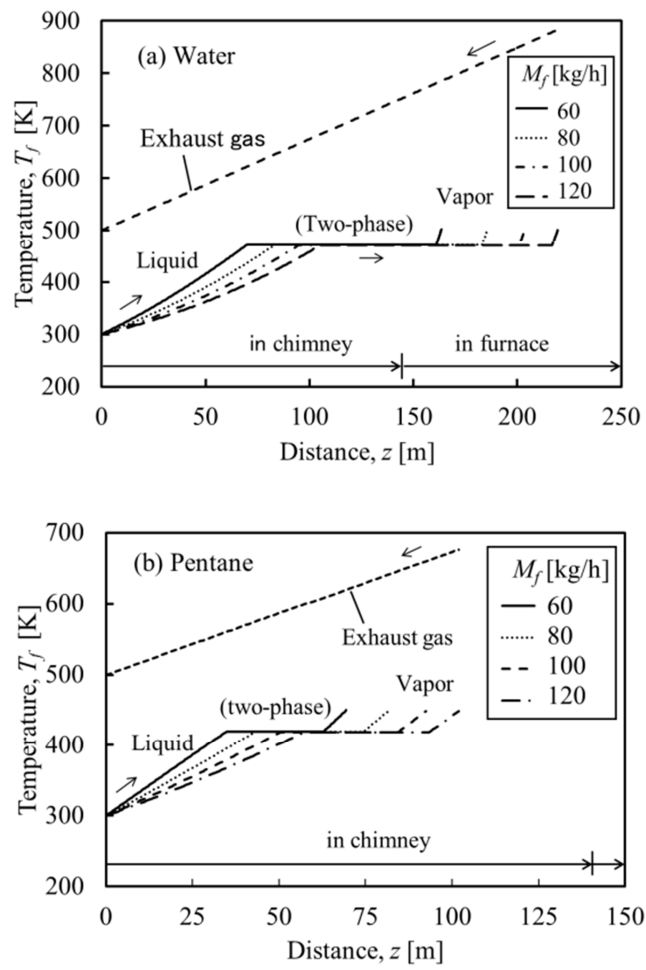

Figure 4. Changes in temperature of working fluid: (a) Water, (b) Pentane.

The estimation of the transition points in the phase change process is crucial on the thermal design of the heat exchanger. Figure 4 present the temperature changes in the working fluid in a single spiral tube with a constant mass flow rate $M_{f}$ ranging from $60-120 \mathrm{~kg} / \mathrm{h}$. The effects of working fluid can understand by comparisons between Figure 4(a) and (b) for water and pentane, respectively. The dotted lines in the figures represent the variation in the gas side temperature by assumption utilized the temperature distributions in Figure 2. Initially, $T_{f}$ increases gradually, then remains nearly constant in the two-phase region, and finally increases gradually again in the gas phase region. This tendency of the temperature profile is similar for both water and pentane. This calculation is useful for estimating the transition of the phase change in spiral tube.

The distance to the transition of the phase change moves toward the down-flow side with an increasing $M_{f}$. This means that a longer heat transfer distance is required to obtain the larger amount of desired superheated vapor. In the case of water, the tube outlet reaches a distance of more than $150 \mathrm{~m}$ and is located inside the combustion chamber through chimney. In case of pentane, the outlet reaches a relatively short distance compared to water and is located inside the chimney.

Figure 5(a) and (b) present comparisons of the overall heat recovery $Q_{h}$ for water and pentane flowing with the same $M_{f}$. The notation $Q_{h}$ in the bar graph refers to the integrated values in the liquid phase region, two-phase region, and gas phase region, respectively. $Q_{h}$ increases nearly linearly with an increasing $M_{f}$ for both water and pentane.

The $Q_{h}$ ranges from 45 - $95 \mathrm{~kW}$ for water and $10-20 \mathrm{~kW}$ for pentane, which indicates that the heat recovery rate of water is approximately 4.5 times that of pentane in the $M_{f}$ range of 45 $95 \mathrm{~kg} / \mathrm{h}$. The ratios of heat recovery in the two-phase region for water and pentane are approximately $72 \%$ and $39 \%$, respectively. This means a relatively larger heat recovery rate is obtained in the two-phase region for water with large latent heat.

Figure 6 presents comparisons of the overall tube lengths $Z_{e x}$ for three types of working fluids: water, pentane, and butane. The vertical axis in the graph represents both the $Z_{e x}$ and $y_{e x}$ axis for the spiral tube heat exchanger. $Z_{e x}$ corresponds to the estimated distance to the outlet to obtain the desired superheated vapor of $50 \mathrm{~K} . Z_{e x}$ increases nearly linearly with increasing $M_{f}$. For an example at $M_{f}=120 \mathrm{~kg} / \mathrm{h}, Z_{e x}$ represents $220 \mathrm{~m}$ for water, $102 \mathrm{~m}$ for pentane, and $88 \mathrm{~m}$ for butane. $Z_{e x}$ shows significant differences between working fluids.
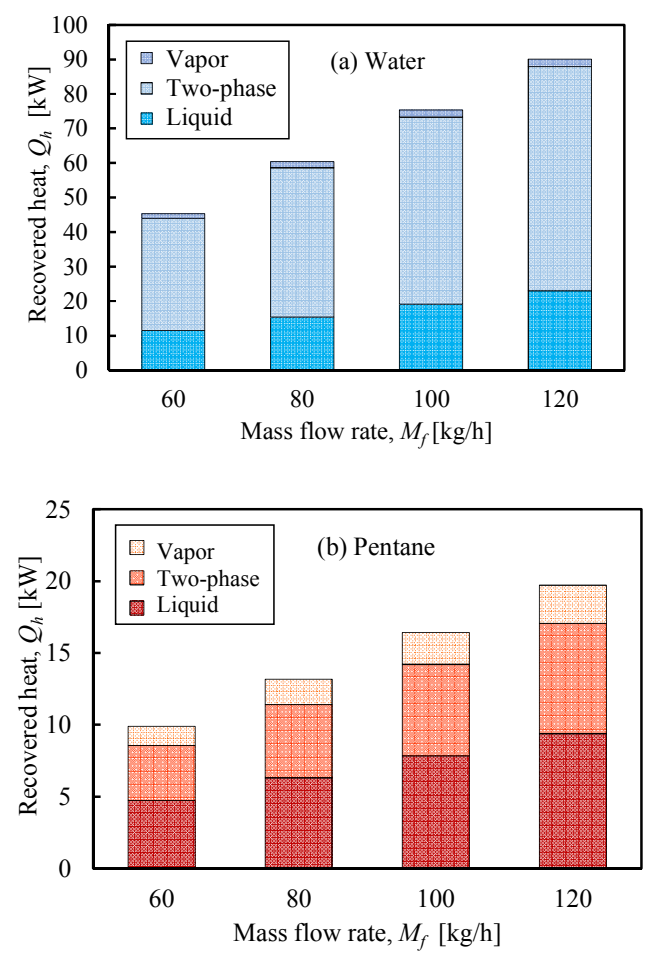

Figure 5. Amount of recovered heat with changing mass flow rate: (a) Water, (b) Pentane. 


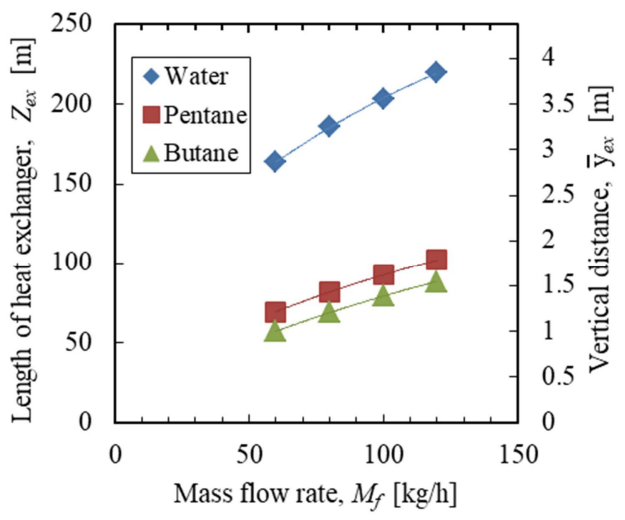

Figure 6. Comparisons of overall tube length.

\subsection{Pressure Drop in Tube}

Figure 7 presents comparisons of pressure drops per unit length in the helical tube for three types of working fluids. $\Delta p_{e x}$ increases nearly linearly with $M_{f}$ with same tendency for water, pentane and butane, respectively. The $\Delta p_{e x}$ values for pentane and butane are $27-30 \%$ lower than that for water. The difference of the working fluid increases at high flow rate.

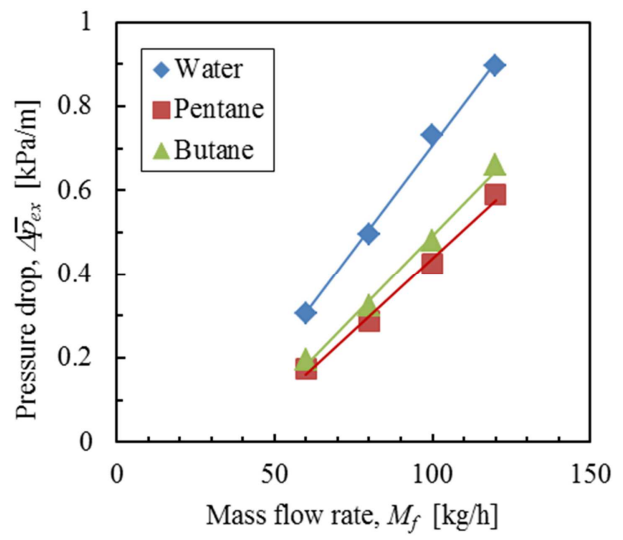

Figure 7. Pressure drop per unit tube length.

\subsection{T-s Diagram and Theoretical Thermal Efficiency}

In order to make a discussion on the potential of the heat recovery-power conversion system, here virtually considers a Rankine cycle combined with this incinerator. Figure 8(a) and (b) present comparisons of the Rankine cycles on the $T-S$ diagrams for two kinds of working fluids of water and pentane, respectively. The superheated vapor obtained by the heat recovery (point $h_{4}$ ) expands adiabatically to the condensation temperature of $T_{c}=310 \mathrm{~K}$, and the maximum theoretical work $L_{t h}=M_{f}\left(h_{4}-h_{5}\right)$ value can be obtained during this process. In the case of water, the superheated vapor at the state $h_{4}$ is considered to enter into the two-phase flow during this process, and it reaches the state of point $h_{5}$ where the water vapor corresponds to the saturation pressure $p_{c}$ for $T_{c}$. In the case of pentane, the superheated vapor at $h_{4}$ reaches $h_{5}$ as the superheated vapor corresponding to the $p_{c}$ for $T_{c}$ and then decreases in temperature until it reaches the point $h{ }_{5}$ of saturated vapor on the isobaric line $\left(p=p_{c}\right)$. From these comparisons of $T-s$ diagrams, it's obvious that the adiabatic heat drop $\Delta h_{a d}$ of water vapor is significantly larger than that of the pentane vapor.
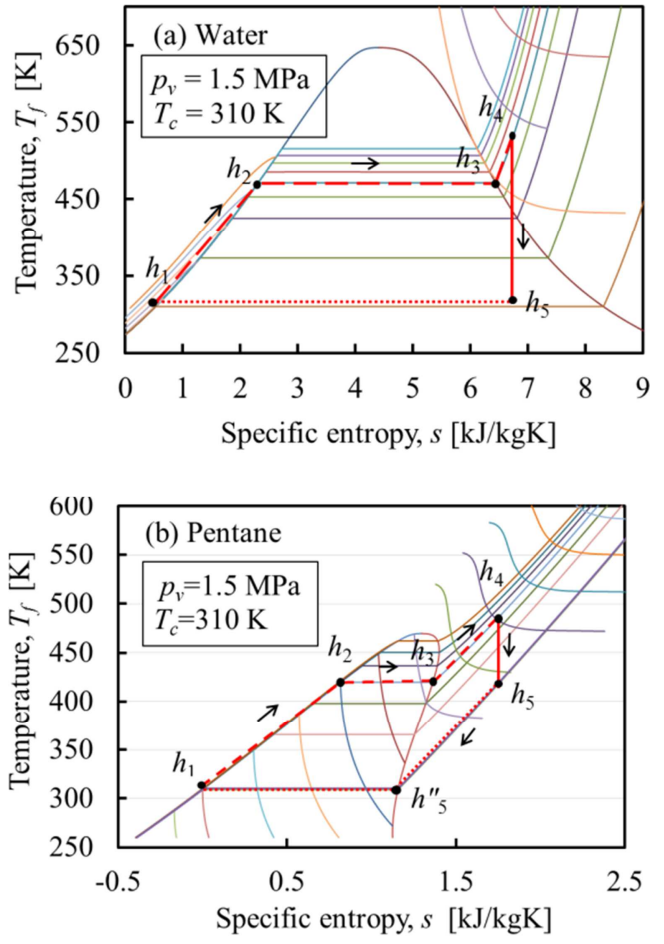

Figure 8. Comparison of Rankine cycles on T-s diagram: (a) Water, (b) Pentane.

The theoretical thermal efficiency $\eta_{t h}$ is defined by $\eta_{t h}=\left(h_{4}\right.$ - $\left.h_{5}\right) /\left(h_{4}-h_{1}\right)$ and utilizes the specific enthalpy values $h_{1-5}$ of each state. Figure 9 presents the effects of condensation temperature on theoretical efficiency. The $\eta_{t h}$ for water ranges from 35 to $30 \%$ in a $T_{c}$ range of $280-320 \mathrm{~K}$, decreases gradually as $T_{c}$ increases. The difference in thermal efficiency between different working fluids is clearly visible.

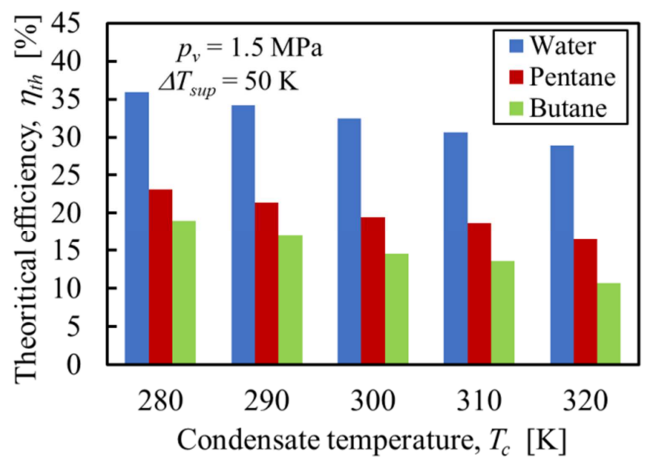

Figure 9. Variation of theoretical thermal efficiency with condensate temperature.

Figure 10 presents the effects of evaporation pressure $p_{e}$ on $\eta_{t h}$ and compares three types of working fluids. $\eta_{t h}$ shows a tendency to slightly increase as $p_{v}$ increases. To summarize the information in Fig. 9 and 10, the $\eta_{t h}$ is higher in the order of water, pentane, and butane. These ranges are $28-36 \%$ for water, $15-23 \%$ for pentane, and $10-18 \%$ for butane in the pv ranges 1-2 MPa. 


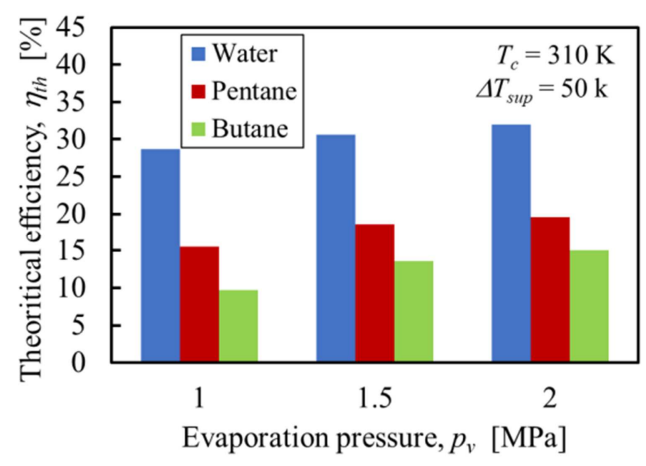

Figure 10. Variation of theoretical thermal efficiency with evaporation temperature.

\subsection{Maximum Heat Recovery and Power Conversion}

By substituting the dimensions $\left(d_{o}=12 \mathrm{~mm}, D_{i}=280 \mathrm{~mm}\right.$, $\mathrm{H}=2.5 \mathrm{~m}, \mathrm{~h}=1.6 \mathrm{~m}$ ) into the Eqs. (13) - (15), the maximum tube length $Z_{e x, \max }$ installable in the furnace can be estimated to be $299 \mathrm{~m}$, with $116 \mathrm{~m}$ in the chimney and $183 \mathrm{~m}$ in the combustion chamber. Considering the obstacles and corners in the actual piping, the maximum tube length within this furnace is considered to be reasonably $Z_{e x, \max }=250 \mathrm{~m}$.

Figure 11 presents the comparison of $Q_{h}$ for three types of working fluids with the $M_{f}$ range $0-150 \mathrm{~kg} / \mathrm{h}$ in a single tube length of $250 \mathrm{~m}$. The amount of critical heat recovery rate within the chimney is approximately expressed by the dotted line in this figure. In the case of water, $Q_{h}$ gradually increases with $M_{f}$ and reaches a maximum value around $M_{f}=150 \mathrm{~kg} / \mathrm{h}$. This means that the tube end for water cannot reach the desired superheated vapor at $M_{f}>150 \mathrm{~kg} / \mathrm{h}$ because the tube length has already reached the maximum. In contrast, in the case of pentane and butane, $Z_{e x}$ has not reached the maximum length and $Q_{h}$ has not reached the critical value. Hence a much larger amount of superheated vapor can be expected to be recovered in using pentane and butane.

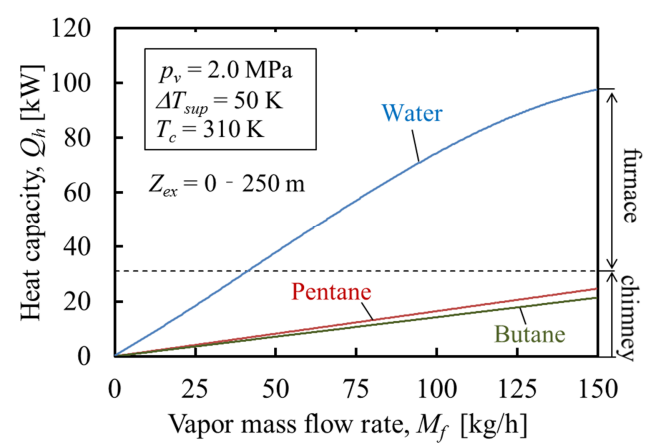

Figure 11. Variation of heat capacity with mass flow rate.

As described in Figures 9 and 10, assuming the average thermal efficiencies $\eta_{\text {th }}$ of each working fluid are $30 \%$ for water, $16 \%$ for pentane, and $12 \%$ for butane, the maximum adiabatic recovery work can be estimated as $L_{a d}=\eta_{t h} Q_{h}$. Additionally, if the external efficiency $\eta_{p}$ of the turbinelinked generator is given, the electric power can be approximately estimated as $E_{p}=\eta_{p} L_{a b}$.

Figure 12 presents the changes in $L_{a d}$ and $E_{p}$ with respect to $M_{f}$ and compares of three types of working fluids. $\eta_{p}$ was given as $30 \%$ refer to [8] and [9]. $L_{a d}$ and $E_{p}$ increase with $M_{f}$, similar to the trend in Fig11. An electric power generation of $11 \mathrm{~kW}$ is estimated at a flow rate $M_{f}=150 \mathrm{~kg} / \mathrm{h}$ when water is utilized as the working fluid. In contrast, the $E_{p}$ values for pentane and butane are less than $2 \mathrm{~kW}$ at $M_{f}=150 \mathrm{~kg} / \mathrm{h}$. However, $E_{p}$ have not reached the maximum values under this condition.

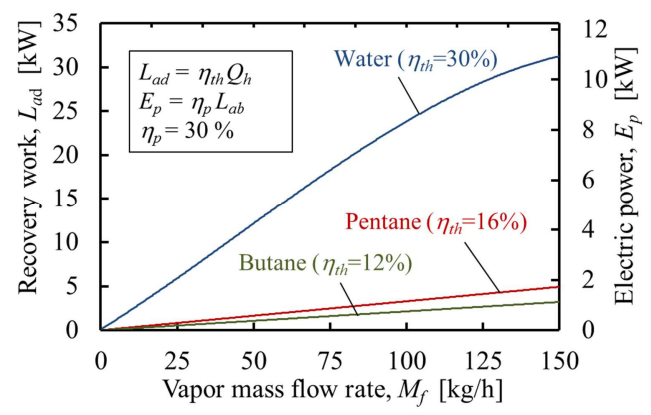

Figure 12. Variation of recovery work and electric power with vapor mass flow rate.

\section{Conclusions}

This study focused on the potential of a micro cogeneration system by estimating the recovered heat from a combustion furnace of a predetermined size. Numerical calculations were performed based on the heat transfer model between the exhaust gas and working fluid assume to use a spiral tube heat exchanger. The key findings from this study are as follows.

(1) When a smooth tube with a diameter of $12 \mathrm{~mm}$ is installed in the form of a spiral along the inner wall of the test furnace shown Figure 1, an overall tube length around $250 \mathrm{~m}$ can be piping for the heat exchanger.

(2) Utilizing water as a working fluid, the heat recovery rate was estimated to be approximately $100 \mathrm{~kW}(31 \mathrm{~kW}$ in chimney, $69 \mathrm{~kW}$ in fire chamber) at a constant flow rate of $150 \mathrm{~kg} / \mathrm{h}$ with a tube of length $250 \mathrm{~m}$.

(3) If the Rankine cycle is operated with the obtained superheated vapor at $p_{v}=1.5 \mathrm{MPa}$ and $T_{c}=310 \mathrm{~K}$, the theoretical thermal efficiency $\eta_{t h}$ ranges from $28-36 \%$ for water, 15 - 23\% for pentane, and $10-18 \%$ for butane.

(4) Assuming that the external efficiency $\eta_{p}$ is $30 \%$, the amount of electric power generation can be approximately estimated as $11 \mathrm{~kW}$ for water and less than $2 \mathrm{~kW}$ for pentane and butane at the same $M_{f}$ value of $150 \mathrm{~kg} / \mathrm{h}$.

(5) The pentane and butane have desirable characteristics as working fluids for heat recovery and dissipating heat with a small temperature difference in narrow spaces because of their lower pressure drops and lower saturation temperatures.

(6) To assess the above conclusions, the experimental investigation should be performed with practical application.

\section{Acknowledgements}

The authors thank for the support of the Okinawa 
Prefecture Science and Technology Innovation Project in 2017-2018. We also appreciate the coordinating of Dr. Y. Nagawa and Dr. I. Matsui of the Okinawa Science and Technology Promotion Center.

\section{Nomenclature}

\begin{tabular}{|c|c|}
\hline $\mathrm{a}, \mathrm{b}, \mathrm{c}, \mathrm{h}, \mathrm{H}$ & dimensions of combustion furnace [m] \\
\hline$c_{n}$ & gas temperature coefficient [-] \\
\hline$d$ & tube diameter $[\mathrm{m}]$ \\
\hline$D$ & diameter of chimney $[\mathrm{m}]$ \\
\hline$g$ & gravitational acceleration $\left[\mathrm{m} / \mathrm{s}^{2}\right]$ \\
\hline$h$ & specific enthalpy $[\mathrm{J} / \mathrm{kg}]$ \\
\hline$M$ & mass flow rate $[\mathrm{kg} / \mathrm{s}]$ or $[\mathrm{kg} / \mathrm{h}]$ \\
\hline$N$ & number of turn [time] \\
\hline$p$ & pressure $[\mathrm{Pa}]$ \\
\hline$\Delta p$ & pressure drop $[\mathrm{Pa}]$ \\
\hline$Q$ & heat transfer rate [W] \\
\hline$q$ & heat flux $\left[\mathrm{W} / \mathrm{m}^{2}\right]$ \\
\hline$R_{c}$ & coil radius of spirally wound tube $[\mathrm{m}]$ \\
\hline$s$ & specific entropy $[\mathrm{J} /(\mathrm{kg} \cdot \mathrm{K})]$ \\
\hline$T$ & temperature $[\mathrm{K}]$ or $\left[{ }^{\circ} \mathrm{C}\right]$ \\
\hline$u$ & velocity $[\mathrm{m} / \mathrm{s}]$ \\
\hline$x$ & quality of working fluids $[-]$ \\
\hline$y$ & vertical coordinate or vertical head $[\mathrm{m}]$ \\
\hline $\bar{y}$ & distance or length $[\mathrm{m}]$ \\
\hline Z & overall tube length $[\mathrm{m}]$ \\
\hline$z$ & spiral coordinate or length of element $[\mathrm{m}]$ \\
\hline$\Delta z_{b}$ & bending loss head of tube element $[\mathrm{m}]$ \\
\hline$\Delta z_{f}$ & friction loss head of tube element [m] \\
\hline$\alpha$ & heat transfer coefficient $\left[\mathrm{W} /\left(\mathrm{m}^{2} \cdot \mathrm{K}\right)\right]$ \\
\hline$\varepsilon$ & emissivity $[-]$ \\
\hline$a$ & absorptivity $[-]$ \\
\hline$\lambda$ & thermal conductivity $[\mathrm{W} /(\mathrm{m} \cdot \mathrm{K})]$ \\
\hline$\sigma$ & Stefan-Boltzmann constant $\left[\mathrm{W} /\left(\mathrm{m}^{2} \cdot \mathrm{K}^{4}\right)\right]$ \\
\hline$\gamma$ & spiral angle [rad.] \\
\hline$\rho$ & density $\left[\mathrm{kg} / \mathrm{m}^{3}\right]$ \\
\hline
\end{tabular}

\section{Subscript}

$\begin{array}{ll}\mathrm{ad} & \text { adiabatic } \\ \mathrm{b} & \text { boiling } \\ \mathrm{c} & \text { convection } \\ \mathrm{ex} & \text { heat exchanger } \\ \mathrm{f} & \text { working fluid } \\ \mathrm{g} & \text { gas or gas side } \\ \mathrm{i} & \text { inside or inner } \\ \mathrm{j} & \text { element's number } \\ \mathrm{l} & \text { loss } \\ \mathrm{o} & \text { outside } \\ \mathrm{p} & \text { power } \\ \mathrm{r} & \text { radiation } \\ \mathrm{w} & \text { wall } \\ \mathrm{wg} & \text { gas side's wall } \\ \mathrm{fg} & \text { fluid side's wall } \\ 0 & \text { inlet } \\ 1 & \text { outlet }\end{array}$

\section{References}

[1] Takuma Co., Ltd., Environmental Technology Research Association, "Waste Incineration Technology", Ohm-Sha, 2010, pp. 1-200.

[2] The Japan Society of Mechanical Engineers, Heat Transfer Data Book 5 th ed., 2009, pp. 105-204.

[3] The Japan Society of Refrigerating and Air Conditioning Engineers, Refrigeration, Special ed., Vol. 090, No. 1047, 2015, pp. 3-22.

[4] R. Echigo, K. Hanamura, Y. Takahashi, M. Okuyama, S. Jugjai, A. Hagiwara, Y. Usami and N. Funahashi, "Heat transfer analysis for a tubular methane-steam reformer with a porous radiative converter", Transactions of the Japan Society of Mechanical Engineers, Series B, Vol. 57, No. 539, 1991, pp. 163-169.

[5] J. Yamashita and Y. Utaka, "On prediction of heat exchanger performance for latent heat recovery using flue gas", Transactions of the Japan Society of Mechanical Engineers, Series B, Vol. 80, No. 818, 2014, pp. 1-14.

[6] A. S. Hegazy, "Possible waste heat recovery in the condenser of a regenerative steam cycle", Journal of Thermal Science and Technology, Vol. 2, No. 1, 2007, pp. 1-12.

[7] H. Takamatsu, H. Yamashiro, N. Takata, H. Honda, "Vapor absorption by $\mathrm{LiBr}$ aqueous solution in vertical smooth tubes", International Journal of Refrigeration, Vol. 26, 2003, pp. 659666.

[8] Le Minh Nhut, Young-Sub Moon, Youn Cheol Park, "A study on energy optimization of heat exchanger in a gasification system", International Journal of Mechanical Engineering and Applications, Vol. 4, No. 3, 2016, pp. 123-129.

[9] H. Hasegawa and S. Kimishima, "An investigation on working fluid selection of Rankine-Cycle driven by low grade heat with small temperature difference to environment", Transactions of the Japan Society of Refrigerating and Air Conditioning Engineers, Vol. 30, No. 1, 2013, pp. 1-12.

[10] P. A. Kew and K. Cornwell, "Development of a highly compact steam generator", Applied Thermal Engineering, Vol. 25,2005 , pp. 2604-2614.

[11] S. Tokuda and T. Osanai, "Exergie-Heat recovery analysis for exhaust gas in the boiler system", Transactions of the Japan Society of Mechanical Engineers, Series B, Vol. 50, No. 449, 1984, pp. 91-97.

[12] Xin, Z. Rao, X. You, Z. Song, D. Han, "Numerical investigation of vapor-liquid heat and mass transfer in porous media", Energy Conversion and Management, Vol. 78, 2014, pp. 1-7.

[13] Fei He, J. Wang, "Numerical investigation on critical heat flux and coolant", Energy Conversion and Management, Vol. 80, 2014, pp. 591-597.

[14] O. R. Alomar, M. A. A. Mendes, D. Trimis, S. Ray, "Numerical simulation of complete liquid-vapour phase change process inside porous media using smoothing of diffusion coefficient", International Journal of Thermal Sciences, Vol. 86, 2014, pp. 408-420. 
[15] O. R. Alomar, M. A. A. Mendes, S. Ray, D. Trimis, "Numerical investigation of complete evaporation process inside porous media using staggered and non-staggered grid arrangements", International Journal of Thermal Sciences, Vol. 129, 2018, pp.56-72.

[16] O. R. Alomar, R. R. Mohammed, M. A. A. Mendes, S. Ray, D. Trimis, "Numerical investigation of two-phase flow in anisotropic porous evaporator", International Journal of Thermal Sciences, Vol. 135, 2019, pp. 1-16.

[17] Lemmon, E. W., Huber, M. L. and Mc Linden, M. O., NIST REFPROP Ver.9 (2010). 